\title{
Direct observation of the oxygen atoms in $\mathrm{UO}_{2+x}$
}

\author{
CHENXU WANG ${ }^{1}$, ARJEN VAN VEELEN ${ }^{2}$, JOHN BARGAR $^{3}$, \\ RODNEY C. EWING ${ }^{1}$
}

${ }^{1}$ Department of Geological Sciences, Stanford University, Stanford, CA, USA (chenxuw@stanford.edu, rewing1@stanford.edu)

${ }^{2}$ Nuclear Materials Science, Los Alamos National Laboratory, Los Alamos, NM, USA (vveelen@slac.stanford.edu)

${ }^{3}$ SLAC National Accelerator Laboratory, Menlo Park, CA, USA (bargar@slac.stanford.edu)

$\mathrm{UO}_{2}$ is the principal fuel in nuclear reactors. The isometric structure also accommodates oxygen interstitials, which have important effects on chemical and physical properties. Computational studies have shown that excess oxygen atoms in $\mathrm{UO}_{2+\mathrm{x}}$ occur as interstitial defects and are partially ordered [1]. However, the exact distribution of the defects has remained controversial. We present the atomic structures and bonding characteristics of a series of $\mathrm{UO}_{2+\mathrm{x}}$ compositions using high-resolution (HR) aberration-corrected transmission electron microscopy (TEM) negative spherical aberration imaging (NCSI), which enables direct observation of light elements (oxygen atoms in $\mathrm{UO}_{2+\mathrm{x}}$ ) as compared with conventional TEM images. Stoichiometric $\mathrm{UO}_{2}$ was synthesized from an uranyl peroxide precursor and oxidized to $\mathrm{UO}_{2+\mathrm{x}}$ under a controlled $\mathrm{Ar} / \mathrm{O}_{2}$ atmosphere. Subsequently, $x$ of $\mathrm{UO}_{2+\mathrm{x}}$ was determined via Thermogravimetric Analysis (TGA). Oxygen atoms are firstly observed at the octahedral anion sites along [100], which is consistent with the TEM image simulation results by JEMS. The role of stoichiometry $(x)$ factor in structure of $\mathrm{UO}_{2+\mathrm{x}}$ and the excess oxygen atoms' locations will be discussed.

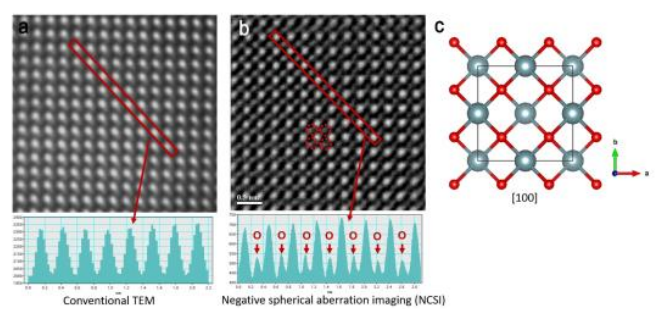

Figure 1. (a) Conventional high-resolution TEM image of a grain in the $\mathrm{UO}_{2.00}$ sample. (b) Negative spherical aberration image obtained from the same grain in (a). The contrast profile along the red squares in $(a, b)$ are indicated by the red arrows. The dotted red circles show the oxygen atoms located at the anion sites. (c) Structural model of $\mathrm{UO}_{2.00}$.

[1] J. Wang, R. C. Ewing, and U. Becker, Average structure and local configuration of excess oxygen in $\mathrm{UO}_{2+\mathrm{x}}$, Sci. Rep. 4, 4216 (2014). 